\title{
Fluoroquinolone-macrolide combination therapy for chronic bacterial prostatitis: retrospective analysis of pathogen eradication rates, inflammatory findings and sexual dysfunction
}

\author{
Vittorio Magri ${ }^{1}$, Emanuele Montanari $^{2}$, Višnja Škerk ${ }^{3}$, Alemka Markotic ${ }^{3}$, Emanuela Marras $^{4}$, Antonella Restelli ${ }^{5}$, \\ Kurt G Naber ${ }^{6}$ and Gianpaolo Perletti ${ }^{4}$
}

\begin{abstract}
We previously demonstrated the safety and efficacy of fluoroquinolone-macrolide combination therapy in category II chronic bacterial prostatitis (CBP). The aim of this study is to retrospectively compare the microbiological and clinical findings of two treatment schemes for CBP based on the combination of azithromycin $(500 \mathrm{mg}$, thrice-weekly) with a once-daily 500 - or 750-mg dose of ciprofloxacin (Cipro-500 or Cipro-750 cohort, respectively). Combined administration of azithromycin (1500 mg week ${ }^{-1}$ ) with ciprofloxacin at the rate of $750 \mathrm{mg} \mathrm{day}^{-1}$ for 4 weeks rather than at $500 \mathrm{mg} \mathrm{day}^{-1}$ for 6 weeks increased the eradication rates from $62.35 \%$ to $77.32 \%$ and the total bacteriological success from $71.76 \%$ to $85.57 \%$. A significant decrease in pain and voiding signs/symptoms and a significant reduction in inflammatory leukocyte counts and serum prostate-specific antigen (PSA) were sustained throughout an 18-month follow-up period in both groups. Ejaculatory pain, haemospermia and premature ejaculation were significantly attenuated on microbiological eradication in both groups, but the latter subsided more promptly in the Cipro-750 cohort. In total, 59 Cipro-750 patients showed mild-to-severe erectile dysfunction (ED) at baseline, while 22 patients had no ED on microbiological eradication and throughout the follow-up period. In conclusion fluoroquinolone-macrolide therapy resulted in pathogen eradication and CBP symptom attenuation, including pain, voiding disturbances and sexual dysfunction. A once-daily $750-\mathrm{mg}$ dose of ciprofloxacin for 4 weeks showed enhanced eradication rates and lower inflammatory white blood cell counts compared to the 500-mg dose for 6 weeks. Our results are open to further prospective validation.
\end{abstract}

Asian Journal of Andrology (2011) 13, 819-827; doi:10.1038/aja.2011.36; published online 18 July 2011

Keywords: azithromycin; chronic bacterial prostatitis; chronic pelvic pain syndrome; ciprofloxacin; erectile dysfunction; International Index of Erectile Function (IIEF); National Institutes of Health Chronic Prostatitis Symptom Index (NIH-CPSI)

\section{INTRODUCTION}

Chronic prostatitis is a serious and invalidating condition that affects a large number of sexually active men worldwide. Chronic prostatitis syndromes have been traditionally classified as bacterial or abacterial. Chronic bacterial prostatitis (CBP, category II, National Institute of Diabetes and Digestive and Kidney Diseases Chronic Prostatitis Workshop, 1995) is diagnosed when segmented lower urinary tract cultures indicate a chronically infected prostate gland as the source of recurrent symptomatic episodes of bacteriuria. ${ }^{1} \mathrm{CBP}$ is characterized by a complex array of symptoms that include pelvic pain, dysuria, urinary frequency/urgency and nycturia, as well as ejaculation and sexual disturbances. ${ }^{2}$ Sexually transmitted organisms are most frequently involved in the disease. Besides traditional uropathogens (Escherichia coli, Klebsiella spp., Proteus spp., Pseudomonas aeruginosa, Enterococcus faecalis and
Staphylococcus aureus), unusual pathogens (Chlamydia trachomatis, other Gram+/- pathogens, Trichomonas vaginalis, Mycoplasmata and Mycobacteria) are reputed to play a causative role in CBP in some cases. ${ }^{3,4}$ Anaerobic bacteria have been proposed to play a pathogenic role in CBP on the basis of studies that show (i) a significant association between the evidence of prostatic infection by anaerobes and the presence of markers of inflammation in prostatic secretions; (ii) a clinical cure or remission following eradication of anaerobic pathogens in patients showing signs and symptoms of CBP; $;^{5-7}$ and (iii) the detection of anaerobes in a higher proportion of symptomatic chronic prostatitis/chronic pelvic pain syndrome patients compared to asymptomatic controls. ${ }^{8}$

Owing to the introduction of fluoroquinolones as first-line antibacterial agents for CBP, higher eradication rates $(70 \%-80 \%)$ have been reported, which have improved over the rates previously

${ }^{1}$ Urology and Sonography Secondary Care Clinic, Azienda Ospedaliera Istituti Clinici di Perfezionamento, Milano 20132, Italy; ${ }^{2}$ Clinica Urologica III, University of Milan/San Paolo Hospital, Milano 20142, Italy; ${ }^{3}$ University Hospital for Infectious Diseases ‘Dr. Fran Mihaljevic', Zagreb 10000 , Croatia; ${ }^{4}$ Laboratory of Toxicology and Pharmacology, Department of Biomedical, Informatic, Environmental and Communication Sciences, Università degli Studi dell'Insubria, Busto A.Narese 21052 , Italy; ${ }^{5}$ Microbiology Unit, Fondazione IRCCS Osp. Maggiore Policlinico Mangiagalli Regina Elena, Milano 20122, Italy and ${ }^{6}$ Technical University, Munich 80333, Germany

Correspondence: Dr G Perletti (gianpaolo.perletti@uninsubria.it)

Received: 14 December 2010; Revised: 1 February 2011; Accepted: 21 March 2011; Published online: 18 July 2011 
achieved by administration of cotrimoxazole (30\%-65\%). ${ }^{9}$ Although these results are encouraging, CBP-causative pathogens are not eradicated in about $20 \%-25 \%$ of the cases. Moreover, pathogen eradication is often only apparent, as eradication rates frequently drop in the months following treatment. ${ }^{10}$ This is probably due to the fact that the pharmacokinetics of certain fluoroquinolones is suboptimal and that the fluoroquinolone concentration within prostatic secretions is relatively low and frequently overlaps with pathogen sensitivity breakpoints or mutant-prevention concentrations. ${ }^{11,12}$

Relapse due to incomplete pathogen eradication is also likely to occur because of the transition of planktonic bacteria to sessile, chemoresistant, quorum sensing-activated biofilms. ${ }^{13-15}$ For these reasons, current pharmacological research in the field of bacterial prostatitis also focuses on the investigation of new prostatotropic antibacterials or on the optimisation of dosages and combinations of available antibiotics. ${ }^{16,17}$

We previously reported the outcome of a 6-week combination therapy protocol administered to CBP patients that was based on a single 500-mg daily dose of ciprofloxacin (cumulative dose: $21 \mathrm{~g}$ ) and a thrice-weekly 500-mg dose of azithromycin. ${ }^{18}$ Although treatment was effective and well tolerated, patients described the treatment as lengthy and difficult to comply with. In addition, in about $35 \%$ of the cases, a second course of treatment was necessary to achieve permanent eradication of the causative pathogens. ${ }^{18}$ In an attempt to combine better eradication rates with shorter courses of treatment, this therapeutic scheme was subsequently modified to administer the same cumulative dose of $21 \mathrm{~g}$ of ciprofloxacin at the rate of $750 \mathrm{mg}$ day $^{-1}$ for 4 weeks. The present retrospective study was aimed at comparing the microbiological, microscopic and clinical findings of the two treatment schemes. The effect of combination therapy on sexual dysfunction, frequently observed in chronic prostatitis patients, was analysed in detail.

\section{MATERIALS AND METHODS}

The Ethics Committee of the Principal Investigator's Hospital was notified of the present study according to Italian bylaws (Determinazione AIFA 20/3/2008, GU 76, 31/3/2008). Patients provided written consent for processing and anonymous publication of their clinical data.

This manuscript was prepared in adherence to the Strengthening the Reporting of Observational Studies in Epidemiology Statement (STROBE) guidelines for good reporting of observational studies. ${ }^{19}$ The present study was independent of institutional or industry funding.

\section{Inclusion criteria}

This cohort study was based on the retrospective analysis of a database of over 1100 patients who were diagnosed and treated in a single secondary care urological centre that specialized in the treatment of prostatitis syndromes and urological infections, the Istituti Clinici di Perfezionamento, Milan, Italy. All patients consecutively diagnosed with CBP from the year 2000 to 2008 were considered for this study.

Patients between 20 and 59 years of age were included in this study if at a first visit they manifested the signs and symptoms of category II $\mathrm{CBP}$, according to the National Institutes of Health (NIH) criteria (National Institute of Diabetes and Digestive and Kidney Diseases Chronic Prostatitis Workshop, 1995), which lasted at least 3 months within the previous 6 months. Signs/symptoms included dysuria, perineal/testicular pain or discomfort, painful ejaculation, urinary frequency, urgency, hesitancy, nycturia, urinary retention or decreased urinary stream, prostate sonographic abnormality, and prostate asymmetry and/or tenderness during digital rectal examination.

CBP patients were not considered for this study if they presented any of the following conditions: category I acute bacterial prostatitis, chlamydial chronic prostatitis, category III chronic prostatitis/chronic pelvic pain syndrome, therapy with antibacterial agents or other medications effective at the prostatic level within a 90-day period prior to prostatitis diagnosis, renal/hepatic/cardiac insufficiency, arrhythmia or long QT syndrome, indwelling catheters, cystostomy, ureterostomy, previous prostatic surgery or radiotherapy, a prostate volume exceeding $40 \mathrm{ml}$, neoplasia, incomplete compliance to therapy as assessed by interviewing patients at test-of-cure visits, missing data or dropouts at test-of-cure visits or at visits performed 6 or 12 months thereafter, or any serious disease or condition that might represent a major confounder in the evaluation of the patients' quality of life according to the National Institutes of Health Chronic Prostatitis Symptom Index (NIH-CPSI).

\section{Diagnostic procedures}

Published recommendations and international guidelines were followed for the diagnosis of CBP. ${ }^{20,21}$ Briefly, the patient evaluation was based on clinical history, a urological visit including a digitorectal examination, pelvic and transrectal ultrasound, urine flowmetry (maximum urinary flow rate $\left(Q_{\max }\right)$ in $\mathrm{ml} \mathrm{s}^{-1}$, waiting time, average flow rate, time to maximum flow, flow time, voiding time and voided volume, performed with a MENFIS-Picoflow 2 uroflowmeter (Digitimer Ltd, Welwyn Garden City, UK) on patients not allowed to void for $2 \mathrm{~h}$ prior to the test) and on microbiological analysis based on the "4-glass" lower urinary tract segmented localisation test. ${ }^{22}$ Following the prostatic massage needed to obtain expressed prostatic secretions and post-massage voided urine, the total ejaculate was collected and subjected to the same tests as described previously. ${ }^{23}$

Total ejaculate was obtained and processed according to the World Health Organization laboratory manual for the examining and processing of human semen. ${ }^{24}$ Patients abstained from sexual intercourse and masturbation for 5-7 days. Before collecting the ejaculate, patients passed urine and washed their hands and penis with disinfecting detergents. ${ }^{25}$ The ejaculate, collected in a sterile container, was placed in culture within $180 \mathrm{~min}$. Samples were cultured on solid media (bloodagar, Columbia CNA and chocolate agar (in $\mathrm{CO}_{2}$-enriched atmosphere) or MacConkey and Sabouraud agar (in aerobic conditions)). Microbial growth was evaluated after 24 and $48 \mathrm{~h}$. Pathogens were identified with biochemical and serological techniques, and antimicrobial susceptibility was performed with automated (Vitek 2; BioMerieux Inc., Durham, NC, USA) or manual (Kirby-Bauer, E-test) procedures.

To minimize sustained cross-infection, the sexual partners of the patients were recommended to undergo a gynaecological examination that included cultures from midstream urine and urethral and vaginal swabs. In addition, protected sexual intercourse and condom usage was mandatory for patients during visits, therapeutic interventions and follow-up examinations and was recommended at dismissal.

For the diagnosis of prostatic bacterial infection, colony counts in prostatic specimens were required to be at least tenfold greater than those assessed in midstream urine samples. Inflammatory leukocytes (white blood cells (WBCs)) were counted in expressed prostatic secretions (EPS), voided bladder-3 (VB3) and semen. ${ }^{1}$ In the case of infection by more than one pathogen, microbiological tests were repeated to exclude accidental specimen contamination. A 
validated translation of the NIH-CPSI was used to score the severity of CBP clinical symptoms. ${ }^{26}$

\section{Study outline}

Cipro-750 group ( $\mathrm{n}=97)$. After completing clinical and microbiological evaluations at the baseline visit (visit time point $0, \mathrm{~V} 0$ ), patients were treated for 4 weeks with a fluoroquinolone-macrolide combination described in detail in previous reports. ${ }^{4,18,27}$ An oral once-daily 750-mg dose of ciprofloxacin was combined with a 500-mg dose of azithromycin. Azithromycin was administered only during the first 3 consecutive days at the beginning of each week of treatment with the fluoroquinolone ("pulse therapy"), as previously described. ${ }^{18,28,29}$ In agreement with the algorithm recommended by Wagenlehner and Naber, ${ }^{30}$ patients remained on continuous treatment with the alphaadrenoceptor blocker alfuzosin ER $\left(10 \mathrm{mg} \mathrm{day}^{-1}\right)$ for a period of 6 months, during which time a supplement containing Serenoa repens extract $\left(640 \mathrm{mg} \mathrm{day}^{-1}\right)$, lycopene $\left(5 \mathrm{mg} \mathrm{day}^{-1}\right)$ and selenium $(50 \mu \mathrm{g}$ day $^{-1}$ ) in a single formulation was also administered..$^{31}$ Four weeks after the end of antimicrobial treatment, the patients were subjected to a complete diagnostic protocol, including microbiological and clinical evaluations. This time point was named VERAD (visit for assessment of eradication).

At the V6, V12 and V18 time points $(6,12$ and 18 months after VERAD, respectively), patients were subjected to complete clinical evaluations (visits, instrumental analysis, questionnaires). In patients showing symptom relapse during follow-up, microbiological evaluations were repeated.

Cipro-500 group $(\mathrm{n}=170)$. This patient cohort was treated with an oral once-daily $500-\mathrm{mg}$ dose of fast-release ciprofloxacin combined with a single $500 \mathrm{mg} \mathrm{day}^{-1}$ dose of azithromycin (administered thriceweekly as in the Cipro-750 Group) for 6 weeks. This group also received $10 \mathrm{mg}$ alfuzosin ER and $S$. repens extracts for 6 months.

A mid-therapy compliance assessment of Cipro-750 and Cipro-500 patients consisted of clinical interviews performed by the clinicians at 2 or 3 weeks after V0, respectively. Both Cipro-500 and Cipro-750 cohorts were subjected to the same numbers of standard urological visits and contacts with the urologist-in-charge (VM).

\section{Microbiological response evaluation}

The definitions by Naber et al. ${ }^{10}$ were adopted to report the microbiological response to antibacterial therapy: (i) eradication: baseline pathogen was eradicated $<10^{3} \mathrm{CFU} \mathrm{ml}^{-1}$; (ii) eradication with superinfection: baseline pathogen was eradicated $\left(<10^{3} \mathrm{CFU} \mathrm{ml}{ }^{-1}\right)$ with the appearance of a new pathogen $\left(\geqslant 10^{3} \mathrm{CFU} \mathrm{ml}^{-1}\right)$; (iii) persistence: baseline pathogen was not eradicated $\left(\geqslant 10^{3} \mathrm{CFU} \mathrm{ml}^{-1}\right)$; (iv) persistence with superinfection: baseline pathogen was persistent $\left(\geqslant 10^{3} \mathrm{CFU}\right.$ $\left.\mathrm{ml}^{-1}\right)$ with the appearance of a new pathogen $\left(\geqslant 10^{3} \mathrm{CFU} \mathrm{ml}^{-1}\right)$. We followed the recommendation by Naber et al. ${ }^{10}$ and regarded eradication and eradication with superinfection as bacteriological success.

\section{Evaluation of sexual dysfunction}

The 15-item International Index of Erectile Function (IIEF) was used to score the severity of sexual dysfunction in CBP patients. ${ }^{32}$ Pain at ejaculation and macroscopic haemospermia were assessed at all time points during patient interviews held by the same physician to minimize evaluation bias. Premature ejaculation was evaluated on the basis of self-estimated intravaginal ejaculatory latency time, perceived control, and reported personal and relational distress, in agreement with Hatzimouratidis et al. ${ }^{33}$ Persistence of erectile dysfunction (ED) after antibacterial therapy was defined as an IIEF ED score (the sum of IIEF questions $1,2,3,4,5$ and 15$)<26$. $^{32}$

\section{Data handling and statistical analysis}

To test null hypotheses about intragroup differences in the NIH-CPSI and IIEF scores, we processed our data in the form of ordinal dominance matrices and calculated the Cliff's delta $(\partial)$ for paired data, ${ }^{34}$ the asymmetric $95 \%$ confidence interval (CI) to $\partial$ (calculated using the improved formula by Feng and Cliff ${ }^{35}$ ), and the cumulative probability of $z(\mathrm{z}=\partial / \sqrt{\text { unbiased estimated variance of } \partial}) .^{35,36}$

Intragroup $Q_{\max }$ values before/after therapy and during the followup examinations were analysed using a paired, two-tailed $t$-test.

The absolute values of prostate-specific antigen (PSA) were skewed with a right-hand tail. Non-parametric tests (the Mann-WhitneyWilcoxon test for the comparison of independent groups and the Wilcoxon signed-rank test for matched pairs) were used to analyse the differences in PSA values or leukocyte counts.

Chi-square analysis was used to evaluate differences in the proportions of patients with pyuria, premature ejaculation, haemospermia or ejaculatory pain. This analysis was also used to evaluate the differences in microbiological outcomes and baseline patient presentations. The XLStatistics 5.71 program $^{37}$ and the Ordinal Dominance statistics package for the ' $R$ ' software statistical environment ${ }^{38}$ were used for analysis of data. Our data analysis procedures used 'missing completely at random' assumptions. Results were considered significant at $P<0.05$.

\section{RESULTS}

\section{Microbiological efficacy data}

Table 1 shows the demographic and microbiological presentation of patients at baseline and at the end of treatment (time points V0 to VERAD). About $80 \%$ of the patients in both the Cipro- 500 and Cipro750 groups manifested single-agent infections. Chi-square analysis confirmed the null hypothesis of equal proportions between single and multiple infections in the two cohorts $\left(\chi^{2}=2.16, P=0.14\right)$.

Comparison between the per-patient microbiological outcomes showed a $24 \%$ increase in eradication rates in the Cipro-750 group compared with the Cipro-500 cohort $(77.32 \%$ vs. $62.35 \%$, Table 1) and a $19 \%$ increase in the overall bacteriological success $(85.57 \%$ vs. $71.76 \%)$. The bacteriological failure rate in the Cipro-500 (28.24\%) cohort was increased twofold compared to the Cipro-750 group $(14.43 \%)$. Differences between the eradication $v s$. persistence and success $v$ s. failure proportions were statistically significant $(P=0.003$ and $P=0.01$, respectively; Table 1 ).

Nine patients in each group whose clinical symptoms flared up during the 18-month follow-up showed a relapse of CBP.

Table 2 lists the microorganisms isolated from prostate-specific specimens and the per-pathogen eradication data. Consistent with data in other reports, ${ }^{39}$ the most represented pathogen was Enterococcus faecalis (total 74 isolates) followed by Escherichia coli (57 isolates). In the Cipro-750 group, a significantly higher proportion of eradicated $E$. faecalis was recorded $\left(\chi^{2}=5.15, P=0.023\right.$; Table 2$)$. Intergroup eradication rates of all other pathogens were not different at the statistical level (data not shown).

\section{Clinical efficacy data}

Patient symptom scores were assessed with the NIH-CPSI test. A "clinically relevant improvement", defined by a six-point decrease in the NIH-CPSI total score, ${ }^{40}$ was assessed at VERAD in 75 and 71 patients of the Cipro-500 and Cipro-750 cohorts, respectively $\left(\chi^{2}=5.9, \quad P=0.015\right)$. Therapy caused a marked and statistically 
Table 1 Demographic and microbiological presentation of patients at baseline (time point V0) and at 1 month after antibacterial treatment (time point VERAD)

\begin{tabular}{|c|c|c|c|c|c|}
\hline \multirow{3}{*}{$\begin{array}{l}\text { Demography } \\
\text { Microbiological presentation at baseline }\end{array}$} & \multirow{2}{*}{$\begin{array}{l}\text { Patient cohort } \\
\text { Mean/median age }\end{array}$} & \multicolumn{2}{|c|}{ Cipro-500 $(\mathrm{n}=170)$} & \multicolumn{2}{|c|}{ Cipro- $750^{a}(\mathrm{n}=97)$} \\
\hline & & \multicolumn{2}{|l|}{$45 / 41$} & \multicolumn{2}{|c|}{$46 / 45$} \\
\hline & Single-agent infection, $n(\%)$ & 132 & $(77.65)$ & 83 & $(85.56)$ \\
\hline & Two pathogens, $n(\%)$ & 30 & $(17.65)$ & 13 & $(13.40)$ \\
\hline & Three pathogens, $n(\%)$ & 8 & $(4.70)$ & 1 & $(1.03)$ \\
\hline & Total multiple infections, $n(\%)$ & 38 & $(22.35)$ & 14 & $(14.43)$ \\
\hline & $\chi^{2}$ (single-agent vs. multiple infections) & & $2.16(P=0.14)$ & & \\
\hline \multirow[t]{8}{*}{ Microbiological outcome after therapy } & Eradication, $n(\%)$ & 106 & $(62.35)$ & 75 & $(77.32)$ \\
\hline & Eradication with superinfection, $n(\%)$ & 16 & $(9.41)$ & 8 & $(8.25)$ \\
\hline & Bacteriological success, $n(\%)$ & 122 & $(71.76)$ & 83 & $(85.57)$ \\
\hline & Persistence, $n(\%)$ & 47 & $(27.65)$ & 12 & $(12.37)$ \\
\hline & Persistence with superinfection, $n(\%)$ & 1 & $(0.59)$ & 2 & $(2.06)$ \\
\hline & Bacteriological failure, $n(\%)$ & 48 & $(28.24)$ & 14 & $(14.43)$ \\
\hline & $X^{2}$ (eradication vs. persistence) & & $8.57(P=0.003)$ & & \\
\hline & $\chi^{2}$ (bacteriological success vs. failure) & & $5.9(P=0.015)$ & & \\
\hline
\end{tabular}

${ }^{\text {a }}$ A cohort of patients treated with once-daily 750-mg ciprofloxacin for 4 weeks.

${ }^{\mathrm{b}} \mathrm{A}$ cohort of patients treated with once-daily 500-mg ciprofloxacin for 6 weeks.

significant decrease in pain and voiding symptoms and in the impact of the disease on the patients' quality of life $(P<0.001)$ (Table 3 ). Symptom remission was sustained in patients with microbiological eradication and persisted not only beyond the antibacterial treatment period but also beyond the 6-month alfuzosin/S. repens extended therapy course (Table 3 ). The dropout rates at the V18 time point were limited and similar between cohorts (Cipro-500: 14.71\%; Cipro-750: $16.49 \%$ ), and further sensitivity analysis was considered unnecessary.

Table 2 Microorganisms isolated from prostate-specific specimens and per-pathogen eradication data in Cipro-500 and Cipro-750 ${ }^{\mathrm{b}}$ treatment groups

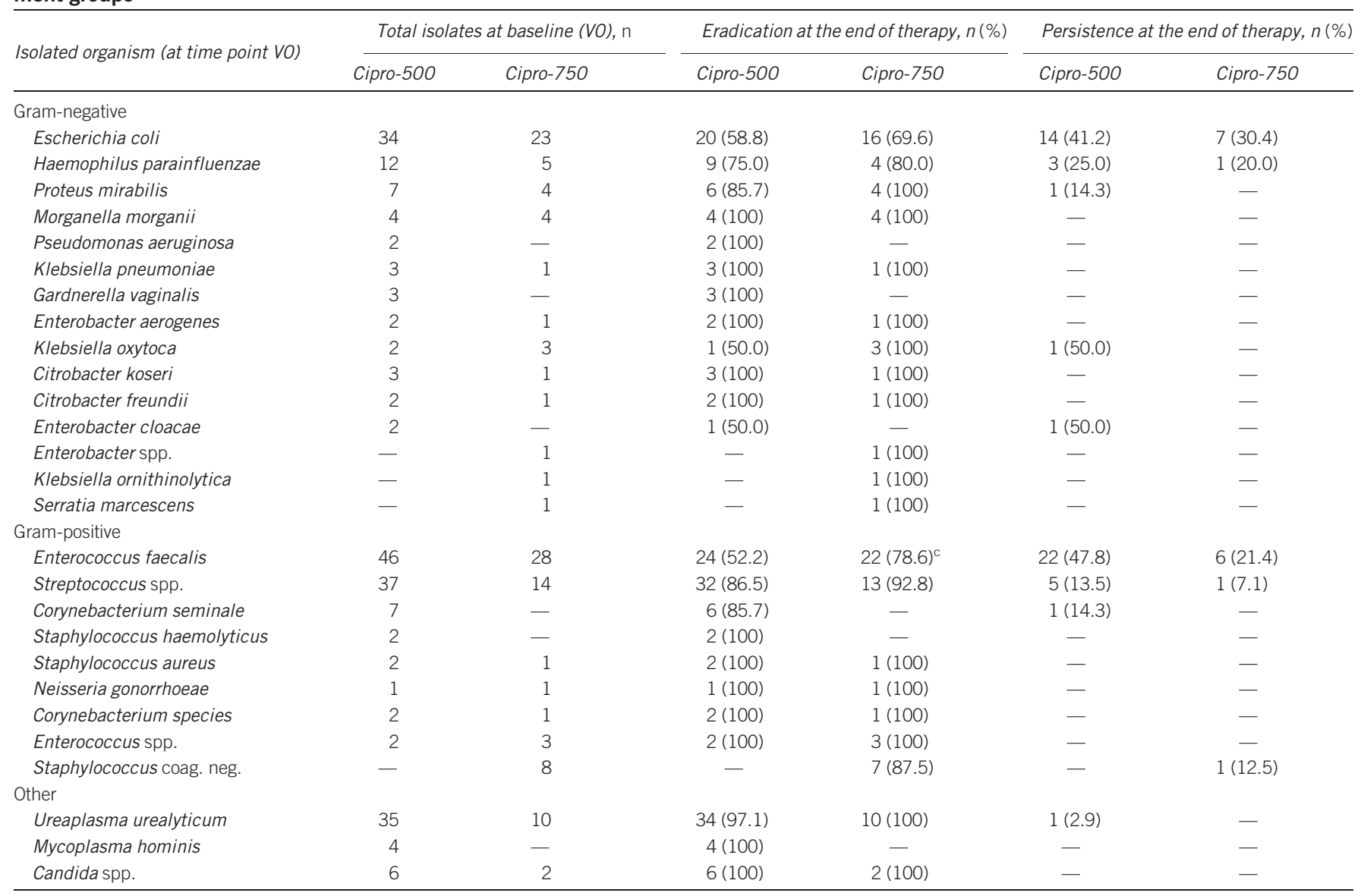

${ }^{\mathrm{a}} \mathrm{A}$ cohort of patients treated with once-daily $500-\mathrm{mg}$ ciprofloxacin for 6 weeks.

${ }^{\mathrm{b}} \mathrm{A}$ cohort of patients treated with once-daily 750 -mg ciprofloxacin for 4 weeks.

${ }^{c} \chi^{2}=5.15, P=0.023$, vs. Cipro-500 cohort. 
Table 3 Cliff's delta $(\partial)$ and $95 \%$ confidence intervals $(\mathrm{CI})$ for delta for the intragroup comparison of the clinical outcome of the combination therapy protocols in the Cipro- $500^{\mathrm{a}}$ and Cipro- $750^{\mathrm{b}}$ cohorts

\begin{tabular}{|c|c|c|c|c|c|c|c|c|}
\hline \multirow{2}{*}{$\begin{array}{l}\text { Cohort } \\
\text { Time point } \\
\text { comparison }\end{array}$} & \multicolumn{4}{|c|}{ Cipro-500 $(n=75)$} & \multicolumn{4}{|c|}{ Cipro-750 $(n=71)$} \\
\hline & VERAD vs. VO & V6 vs. V0 & V6 vs. VERAD & V12 vs. V6 & VERAD vs. VO & V6 vs. V0 & V6 vs. VERAD & V12 vs. V6 \\
\hline \multicolumn{9}{|l|}{$\mathrm{NIH}$-CPSI test } \\
\hline $\begin{array}{l}\text { Total score } \\
\partial(95 \% \mathrm{Cl})\end{array}$ & $\begin{array}{c}-0.78 \\
(-0.84,-0.71) *\end{array}$ & $\begin{array}{c}-0.91 \\
(-0.96,-0.84) *\end{array}$ & $\begin{array}{c}-0.61 \\
(-0.70,-0.49) *\end{array}$ & $\begin{array}{c}-0.0003 \\
(-0.05,0.05)\end{array}$ & $\begin{array}{c}-0.68 \\
(-0.76,-0.59) *\end{array}$ & $\begin{array}{c}-0.93 \\
(-0.96,-0.88) *\end{array}$ & $\begin{array}{c}-0.52 \\
(-0.60,-0.43) *\end{array}$ & $\begin{array}{c}-0.05 \\
(-0.09,-0.01)^{\$}\end{array}$ \\
\hline Pain domain & -0.77 & -0.92 & -0.54 & -0.002 & -0.68 & -0.95 & -0.48 & -0.04 \\
\hline$\partial(95 \% \mathrm{Cl})$ & $(-0.83,-0.69) *$ & $(-0.96,-0.86) *$ & $(-0.63,-0.43)^{*}$ & $(-0.05,0.05)$ & $(-0.76,-0.58) *$ & $(-0.97,-0.89)^{*}$ & $(-0.57,-0.37) *$ & $(-0.09,0.002)$ \\
\hline $\begin{array}{l}\text { Voiding domain } \\
\partial(95 \% \mathrm{Cl})\end{array}$ & $\begin{array}{c}-0.51 \\
(-0.58,-0.42)^{*}\end{array}$ & $\begin{array}{c}-0.69 \\
(-0.77,-0.60) *\end{array}$ & $\begin{array}{c}-0.36 \\
(-0.45,-0.26) * *\end{array}$ & $\begin{array}{c}0.01 \\
(-0.03,0.06)\end{array}$ & $\begin{array}{c}-0.47 \\
(-0.57,-0.37) *\end{array}$ & $\begin{array}{c}-0.71 \\
(-0.80,-0.60) *\end{array}$ & $\begin{array}{c}-0.38 \\
(-0.47,-0.28)^{*}\end{array}$ & $\begin{array}{c}-0.03 \\
(-0.06,0.008)\end{array}$ \\
\hline Impact on quality of & & & & & & & & \\
\hline $\begin{array}{l}\text { life domain } \\
\partial(95 \% \mathrm{Cl})\end{array}$ & $\begin{array}{c}-0.65 \\
(-0.72,-0.55) *\end{array}$ & $\begin{array}{c}-0.86 \\
(-0.92,-0.78) *\end{array}$ & $\begin{array}{c}-0.55 \\
(-0.64,-0.43) *\end{array}$ & $\begin{array}{c}-0.008 \\
(-0.05,0.04)\end{array}$ & $\begin{array}{c}-0.59 \\
(-0.69,-0.47) *\end{array}$ & $\begin{array}{c}-0.83 \\
(-0.89,-0.73)^{*}\end{array}$ & $\begin{array}{c}-0.43 \\
(-0.52,-0.33) *\end{array}$ & $\begin{array}{c}-0.07 \\
(-0.12,-0.03)^{\#}\end{array}$ \\
\hline IIEF test & & & & & & & & \\
\hline $\begin{array}{l}\text { Erectile dysfunction } \\
\partial(95 \% \mathrm{Cl})\end{array}$ & - & - & - & - & $\begin{array}{c}0.19 \\
(0.10,0.27) *\end{array}$ & $\begin{array}{c}0.36 \\
(0.24,0.48)^{*}\end{array}$ & $\begin{array}{c}0.17 \\
(0.08,0.26)^{* *}\end{array}$ & $\begin{array}{c}-0.05 \\
(-0.10,0.003)\end{array}$ \\
\hline Orgasmic & - & - & - & - & & & & \\
\hline dysfunction & & & & & 0.14 & 0.28 & 0.17 & -0.01 \\
\hline$\partial(95 \% \mathrm{Cl})$ & & & & & $(0.04,0.24)^{\#}$ & $(0.16,0.39)^{*}$ & $(0.08,0.26)^{* *}$ & $(-0.09,0.06)$ \\
\hline Sexual desire & - & - & - & - & & & & \\
\hline impairment & & & & & 0.21 & 0.37 & 0.19 & 0.004 \\
\hline$\partial(95 \% \mathrm{Cl})$ & & & & & $(0.12,0.29) *$ & $(0.25,0.48)^{*}$ & $(0.09,0.28)^{*}$ & $(-0.86,0.95)$ \\
\hline Intercourse & - & - & - & - & & & & \\
\hline satisfaction & & & & & 0.25 & 0.39 & 0.18 & 0.06 \\
\hline$\partial(95 \% \mathrm{Cl})$ & & & & & $(0.16,0.34)^{*}$ & $(0.26,0.51)^{*}$ & $(0.08,0.27)^{* *}$ & $(-0.009,0.12)$ \\
\hline $\begin{array}{l}\text { Overall satisfaction } \\
\partial(95 \% \mathrm{CI})\end{array}$ & - & - & - & - & $\begin{array}{c}0.22 \\
(0.13,0.31) *\end{array}$ & $\begin{array}{c}0.38 \\
(0.26,0.49) *\end{array}$ & $\begin{array}{c}0.19 \\
(0.10,0.28) *\end{array}$ & $\begin{array}{c}0.07 \\
(0.01,0.12)^{\$}\end{array}$ \\
\hline
\end{tabular}

National Institutes of Health Chronic Prostatitis Symptom Index (NIH-CPSI) and International Index of Erectile Function (IIEF) tests were used to assess subjective clinical outcomes at time points V0, VERAD, V6, V12 and V18. IIEF data were available for Cipro-750 patients only.

$* P<0.0001$

$* * P<0.001$

${ }^{\#} P<0.01$;

${ }^{\$} P<0.05$

${ }^{a} A$ cohort of patients treated with once-daily 500-mg ciprofloxacin for 6 weeks.

${ }^{\mathrm{b}} \mathrm{A}$ cohort of patients treated with once-daily $750-\mathrm{mg}$ ciprofloxacin for 4 weeks.

'Median values: 27, 14, 7, 7, 6 (Cipro-500) and 22, 12, 7, 7, 6 (Cipro-750) at VO, VERAD, V6, V12, V18, respectively.

${ }^{d}$ Median values: 12, 6, 3, 3, 3 (Cipro-500) and 9, 5, 3, 3, 3 (Cipro-750) at V0, VERAD, V6, V12, V18, respectively.

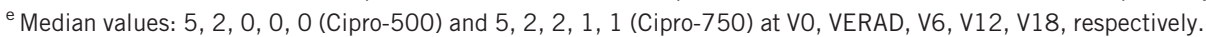

${ }^{f}$ Median values: 9, 6, 3, 3, 3 (Cipro-500) and 8, 4, 3, 3, 3 (Cipro-750) at V0, VERAD, V6, V12, V18, respectively.

${ }^{g}$ Median values: 24, 27, 28, 28, 28 (Cipro-750) at VO, VERAD, V6, V12, V18, respectively.

${ }^{\text {h }}$ Median values: 7, 7, 8, 8, 8 (Cipro-750) at V0, VERAD, V6, V12, V18, respectively.

'Median values: 7, 8, 8, 8, 8 (Cipro-750) at V0, VERAD, V6, V12, V18, respectively.

${ }^{j}$ Median values: 9, 11, 12, 12, 12 (Cipro-750) at V0, VERAD, V6, V12, V18, respectively.

${ }^{\mathrm{k}}$ Median values: 6, 8, 8, 8, 8 (Cipro-750) at V0, VERAD, V6, V12, V18, respectively.

Intragroup differences between baseline (V0) and eradication (VERAD) time points were highly significant in both treatment groups. Intragroup differences between V0 and V6 or between VERAD and V6 time points were also statistically significant (for statistical details, see Table 3 ).

The improvement of voiding symptoms, as assessed with the NIHCPSI test, corresponded to the uroflowmetry data. The urinary peak flow rate was improved in both the Cipro-500 and Cipro-750 groups between V0 and VERAD with highly significant statistical intragroup differences (Figure 1). Further, statistically significant improvements between VERAD and V6 were observed in the Cipro-750 group only. No significant intergroup difference was recorded at any tested time point.

Therapy was well tolerated; mild diarrhoea (loose stool), treated with short courses of probiotics, was the only side effect described by three and two patients in the Cipro-500 and Cipro-750 cohorts, respectively.

\section{Microscopic and biochemical findings}

Table 4 shows WBC counts in the Cipro-500 and Cipro-750 patient cohorts. No significant intergroup differences between WBC counts in VB3/EPS/semen (VB3/EPS, $P=0.14$; semen, $P=0.85$ ) were recorded at baseline (V0). Consistently, patients with frank 'inflammatory' $\left(\mathrm{WBC} \geqslant 10 /\right.$ high-power field $\left.{ }^{41}\right)$ or 'non-inflammatory' $(\mathrm{WBC}<10)$ CBP were present in equal proportions at the V0 time point $\left(\chi^{2}=1.52, P=0.21 ; \chi^{2}=1.45, P=0.22\right)$ in VB3/EPS or semen, respectively. In both cohorts, combination therapy induced a highly significant reduction of WBC counts in all tested specimens and at all analysed time points. Significantly higher WBC counts were observed in patients that showed microbiological persistence (Table 4). Intergroup analysis at VERAD showed significantly lower WBC counts in the Cipro-750 cohort than in the Cipro-500 cohort. In both cohorts, a marked decrease in patients that manifested 'inflammatory' specimens was observed. However, figures were more striking in the Cipro-750 cohort (Table 4). 


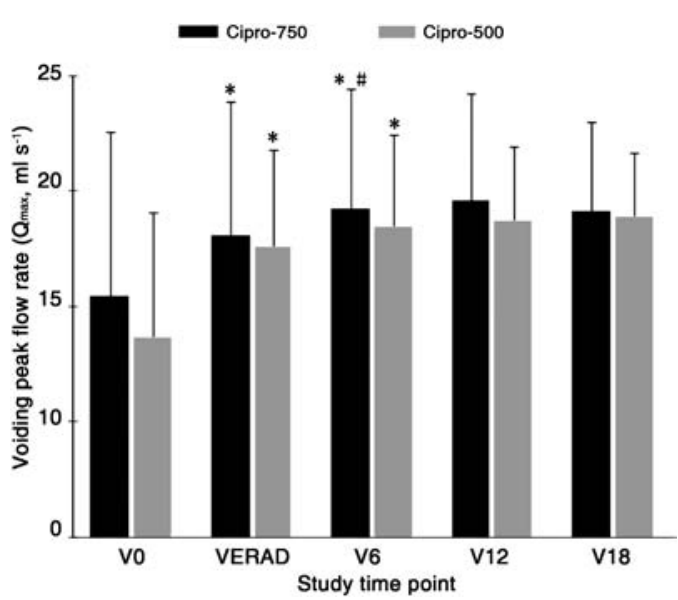

Figure 1 Urine peak flow rate $\left(Q_{\max }\right)$ (mean \pm s.d., $\mathrm{ml} \mathrm{s}^{-1}$ ) in patients in the Cipro-750 (black bars) and Cipro-500 (grey bars) treatment groups. After the assessment of microbiological eradication (time point VERAD), patients were examined every 6 months during an 18-month follow-up period (V6-V18). ${ }^{*} P<0.0001$, compared with V0; ${ }^{*} P=0.01$, compared with VERAD; with paired, two-tailed $t$-test.

Whereas Cipro-750 patients showed significant decreases $(P=0.0036)$ in the average total serum PSA following pathogen eradication, no significant changes were observed in patients treated with lower daily doses of ciprofloxacin (Cipro-500 group; Table 4). However, a significant drop in the PSA was recorded in this group at later follow-up time points (e.g., V6). Intergroup differences were statistically significant at the V6 and V18 time points $(P=0.015, P=0.018)$ (Table 4).

\section{Effect of combination treatment on sexual dysfunction}

Due to the observational nature of our study, we could evaluate sexual dysfunction by the IIEF test only on the more recently treated group, i.e., the Cipro-750 patient cohort. Table 3 summarizes Cliff's delta statistics for each sexual function score assessed with the IIEF test. Combination therapy induced statistically significant improvements in all IIEF subdomain scores, including erectile and orgasmic function, libido and intercourse/overall satisfaction (Table 3).

Of the 97 Cipro-750 patients, 35 had normal erectile function at V0, and three patients were not sexually active. Interestingly, of the remaining 59 patients that showed erectile dysfunction at V0, 22 (37.29\%) experienced no ED at VERAD $(P<0.0001$, statistical inference for Cliff s delta). The other 37 patients who did not show sexual function improvement at VERAD were considered likely candidates for therapy with phosphodiesterase type 5 (PDE-5) inhibitors.

Additional signs/symptoms related to sexual dysfunction were recorded and are summarized in Figure 2. These signs and symptoms were attenuated on microbiological eradication, with the exception of premature ejaculation in the Cipro-500 group (Figure 2). The proportions of Cipro-500 or Cipro-750 patients that showed premature ejaculation did not differ significantly between baseline (V0) and microbiological eradication (VERAD) $\left(\chi^{2}=1.91, P=0.16\right)$. However, significant differences were observed between V0 and V6 $\left(\chi^{2}=11.64\right.$, $P=0.0006)$ and VERAD and V6 $\left(\chi^{2}=4.96, P=0.025\right)$, as only nine out of 97 Cipro-750 patients (9.3\%) showed premature ejaculation at the V6 follow-up time point.

\section{DISCUSSION}

Fluoroquinolones are currently considered first-choice agents against sensitive uropathogens in chronic bacterial prostatitis
(European Association of Urology guidelines ${ }^{20}$ ). A recent review article summarizing the results of six chronic bacterial prostatitis studies showed that ciprofloxacin, administered as a single agent at a dose of $1 \mathrm{~g} \mathrm{day}^{-1}$ for 4 weeks, results in eradication rates ranging between $63 \%$ and $77 \%{ }^{42}$

The present study shows that in chronic bacterial prostatitis, the daily dosage of the fluoroquinolone is more crucial than the duration of therapy, as administration of the cumulative dose of $21 \mathrm{~g}$ of ciprofloxacin at the rate of $750 \mathrm{mg}$ day $^{-1}$ for 4 weeks, rather than $500 \mathrm{mg}$ day $^{-1}$ for 6 weeks, increased eradication rates from $62.35 \%$ to $77.32 \%$ and the total bacteriological success from $71.76 \%$ to $85.57 \%$. In particular, increased eradication of Enterococci was observed in the Cipro750 cohort. As mentioned above, the distribution of ciprofloxacin to prostatic secretions is suboptimal, reaching, for example, the concentration of $0.18 \mathrm{mg} \mathrm{l}^{-1}$ after a single dose of $400 \mathrm{mg}$. ${ }^{17}$ For this reason, ciprofloxacin may not have been active on a number of enterococcal isolates exposed to a daily 500-mg dose of the quinolone, as Enterococcus isolates in complicated urinary tract infections mostly show minimum inhibitory concentrations above $0.5 \mathrm{mg} \mathrm{l}^{-1}$ (for example, see Ref. 30). The increased dosage of ciprofloxacin likely resulted in enhanced bioavailability and prostate distribution and was thus possibly better in exploiting the concentration-dependent bactericidal activity of the quinolone on Enterococci, as well as on other pathogens, such as E. coli.

To provide additional evidence on the efficacy of a fluoroquinolone-macrolide combination compared to single-agent treatment, the Croatian co-authors of this paper recently performed a retrospective study ${ }^{43}$ in a cohort of 60 consecutively enrolled CBP patients. The combination of $500 \mathrm{mg} \mathrm{day}^{-1}$ azithromycin (thrice-weekly, the first 3 consecutive days of each week as in the present trial) and $1000 \mathrm{mg}$ day $^{-1}$ ciprofloxacin for 4 weeks resulted in pathogen eradication in $83.9 \%$ of the cases (assessed at 4 weeks post-therapy), whereas singleagent ciprofloxacin treatment ( $1000 \mathrm{mg} \mathrm{day}^{-1}$ for 4 weeks) resulted in a much lower rate of microbiological eradication (62\%). Importantly, in the Croatian cohort, ciprofloxacin-azithromycin combination therapy was associated with a lower CBP relapse rate $(22.6 \%$ at 6 months) compared with ciprofloxacin single-agent therapy in their study $(48.3 \%)$ and published monotherapy studies (28\% in two studies by Bundrick et al. ${ }^{39}$ and Naber et al. ${ }^{10}$ ). A strikingly low infection relapse rate was recorded in the present retrospective study. However, these results must be evaluated conservatively, since only patients that showed clinical symptom exacerbation during follow-up were subjected to microbiological tests.

In summary, if our data are confirmed in a randomized prospective setting, the combination of ciprofloxacin and azithromycin may provide a therapeutic advantage over single-agent ciprofloxacin administration. Favourable short- and long-term effects of ciprofloxacin-azithromycin therapy may be due to the combination of a number of important and advantageous properties of fluoroquinolones and macrolides. Macrolides have recently, for the first time, been recommended for treatment of chronic prostatitis syndromes ${ }^{44}$ due to their excellent prostatic penetration ${ }^{45}$ and their activity against intracellular and sexually-transmitted pathogens like C. trachomatis. In addition to their antibacterial activity, macrolides show a number of biological effects of great importance, including antibiofilm, anti-inflammatory and immunomodulatory activities. ${ }^{46-49}$

An interesting outcome of the present study was the significant improvement in sexual function following antibacterial therapy. This is to our knowledge the first report providing the rate of erectile function improvement in CBP patients subjected to 
Table 4 White blood cell (WBC) counts in prostate-specific specimens at baseline (time point V0) and after treatment in patients from the Cipro-500 and Cipro-750 groups that show eradication or persistence of causative pathogens, and serum prostate-specific antigen (PSA) at baseline (V0), on microbiological eradication (VERAD), and at follow-up time points (V6, V12 and V18) in the Cipro-500 and Cipro-750 treatment groups

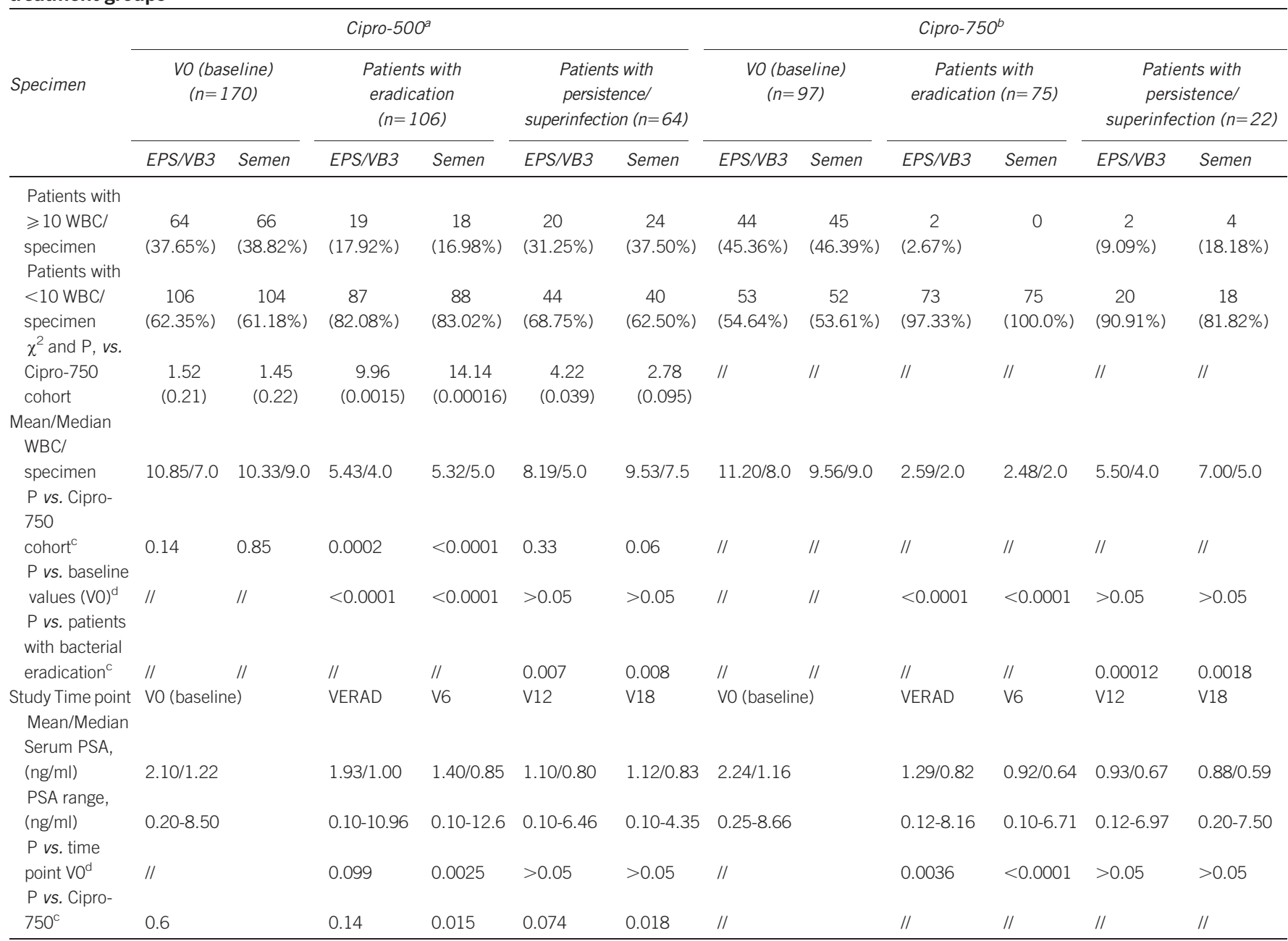

${ }^{a}$ A cohort of patients treated with once-daily 500-mg ciprofloxacin for 6 weeks, combined with azithromycin.

${ }^{\mathrm{b}} \mathrm{A}$ cohort of patients treated with once-daily 500-mg ciprofloxacin for 4 weeks, combined with azithromycin.

${ }^{c}$ Wilcoxon rank-sum test;

${ }^{\mathrm{d}}$ Wilcoxon signed-rank test.

antibacterial treatment. Although the mechanism underlying sexual function improvement remains to be investigated, and although a placebo component of such improvement cannot be excluded, rapid eradication of causative pathogens by the ciprofloxacinazithromycin combination that is likely associated with prompt resolution of the inflammatory component of CBP may have been implicated in the recovery of optimal function of the intraprostatic afferents of cavernous nerves. Normalisation of neuronal homeostasis may thus have aided in the improvement of erectile function in our patient series.

Sexual dysfunction is very common in patients suffering from both bacterial and abacterial chronic prostatitis syndromes, and it may vary between $40 \%$ and $70 \%$, depending on the survey methods and on the populations examined. ${ }^{50-54}$ Sexual dysfunction may manifest as ED, orgasmic/ejaculatory dysfunction or altered libido, and has a deleterious effect on the relationship of prostatitis patients. ${ }^{55-57}$ Moreover, a significantly higher impact of chronic prostatitis/chronic pelvic pain syndrome on the quality of life
(NIH-CPSI domain 3) has been demonstrated in patients with sexual dysfunction when compared to patients with normal sexual function. ${ }^{50,54}$ For these reasons, resolution or attenuation of erectile impairment and of other signs/symptoms related to sexual dysfunction is a primary therapeutic goal. In this report, we have shown that ED disappeared after one cycle of combination treatment in $37 \%$ of affected patients and did not seem to relapse over a follow-up period of 18 months. Administration of PDE-5 inhibitors (vardenafil or tadalafil on-demand) restored a satisfactory sexual function in almost all remaining eligible patients (data not shown). These data suggest a two-stage algorithmic approach to sexual dysfunction in CBP patients, whereby only patients not showing improvement in erectile function after antibacterial therapy should be subjected to specific PDE5-I treatment. In the case of an inadequate PDE5-I treatment outcome, patients may undergo a secondlevel clinical investigation to ascertain vascular, metabolic or cardiovascular conditions and may be subjected to alternative treatment options, according to international guidelines. ${ }^{33}$ 


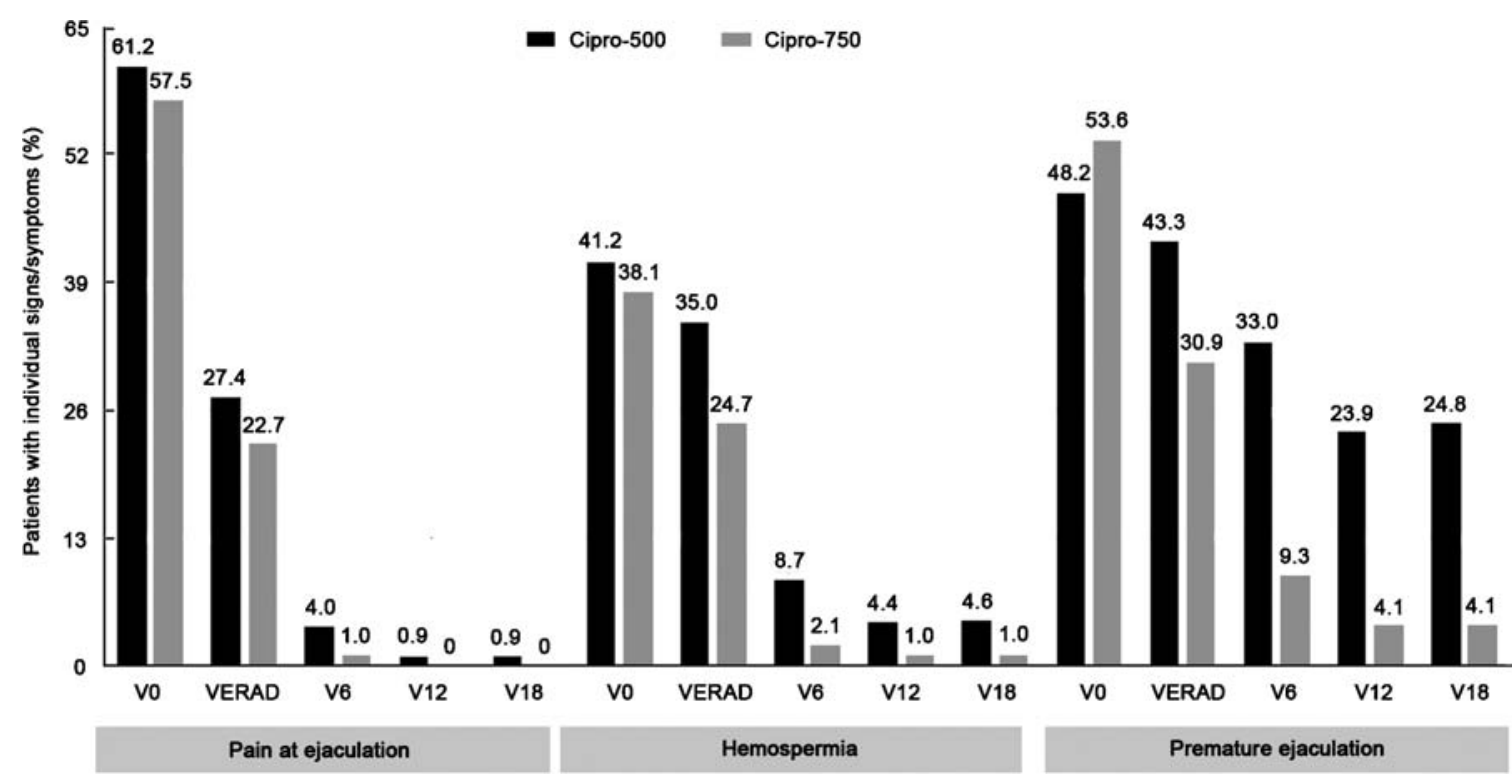

Figure 2 Pain at ejaculation, haemospermia and premature ejaculation in patients in the Cipro-750 (grey bars) and Cipro-500 (black bars) treatment groups. After the assessment of microbiological eradication (time point VERAD), patients were examined every 6 months during an 18-month follow-up period (V6-V18). The percentage of patients with individual symptoms is presented. Frequency of pain at ejaculation in Cipro- 500 vs. Cipro-750 treatment groups between baseline (VO) and microbiological eradication (VERAD) time points: $\chi^{2}=0.16, P=0.68$. Frequency of haemospermia in Cipro-500 vs. Cipro-750 treatment groups between baseline (VO) and microbiological eradication (VERAD) time points: $\chi^{2}=0.75, P=0.38$. Frequency of premature ejaculation in Cipro-500 vs. Cipro-750 treatment groups between baseline (VO) and microbiological eradication (VERAD) time points: $\chi^{2}=1.91, P=0.16$; between VO and V6: $\chi^{2}=11.64, P=0.0006$; between VERAD and V6: $\chi^{2}=4.96, P=0.025$.

Although we strived to minimize all possible sources of bias by following the STROBE guidelines, the present study should be interpreted conservatively because of its observational nature. Nevertheless, our findings may convey two important implications. First, we have shown that ED occurring in patients affected by CBP may be reversible. Second, it appears that antibacterial treatment may improve or cure ED in CBP patients. The latter observation must be taken cautiously, as patients were on chronic treatment with agents (alpha-blockers and S. repens extracts) that may have aided in the improvement of the patients' sexual function. In particular, alphaadrenoceptor blockers are known to be involved in the attenuation of neurogenic inflammation, ${ }^{58}$ whereas S. repens, lycopene and selenium show anti-inflammatory and anti-oxidant properties. ${ }^{31,59}$ However, follow-up data show that the suspension of alpha-blocker or S. repens therapy 6 months after the end of antibacterial treatment was not associated with a worsening of erectile function or premature ejaculation, ${ }^{60}$ thus suggesting that the resolution of bacterial infection was the leading cause of sexual function improvement.

Similarly, pain and voiding symptoms did not deteriorate when patients were off alpha-blockers or herbal extracts, also suggesting that the improvement in CBP signs and symptoms was possibly linked to uropathogen eradication rather than to temporary symptomatic relief evoked by these medications. In conclusion, combination antibacterial treatment appears to be a safe and effective therapeutic option for the long-term eradication of causative pathogens and for long-term resolution of CBP signs and symptoms.

\section{AUTHOR CONTRIBUTIONS}

VM supervised and performed the clinical part of the study. EM collaborated in the clinical part of the study. VŠ and AM; conducted a section of the study (described in the discussion) in their institution and provided unpublished clinical data. EM performed data collection and analysis and assisted in manuscript elaboration.
AR collaborated in the microbiological section of the study. KGN contributed intellectually to data interpretation and MS preparation. GP assisted in the clinical pharmacology section of the study, designed the study, performed statistical analysis and prepared the manuscript.

\section{COMPETING FINANCIAL INTERESTS}

The authors declare that they have no competing financial interests.

\section{ACKNOWLEDGMENTS}

We are thankful to Marta Conti for assistance in database analysis, and to registered nurses Monica Bertocchi, Teresa Rossoni and Giusi Meli for skillful clinical assistance.

1 Krieger JN, Nyberg L Jr, Nickel JC. NIH consensus definition and classification of prostatitis. JAMA 1999; 282: 236-7.

2 Wagenlehner FM, Weidner W, Naber KG. Therapy for prostatitis, with emphasis on bacterial prostatitis. Expert Opin Pharmacother 2007; 8: 1667-74.

3 Skerk V, Krhen I, Schonwald S, Cajic V, Markovinovic L et al. The role of unusual pathogens in prostatitis syndrome. Int J Antimicrob Agents 2004; 24: S53-6.

4 Magri V, Trinchieri A, Ceriani I, Marras E, Perletti G. Eradication of unusual pathogens by combination pharmacological therapy is paralleled by improvement of signs and symptoms of chronic prostatitis syndrome. Arch Ital Urol Androl 2007; 79: 93-8.

5 Berger RE, Krieger JN, Rothman I, Muller CH, Hillier SL. Bacteria in the prostate tissue of men with idiopathic prostatic inflammation. J Urol 1997; 157: 863-5.

6 Szöke I, Török L, Dósa E, Nagy E, Scultéty S. The possible role of anaerobic bacteria in chronic prostatitis. Int J Androl 1998; 21: 163-8.

7 Magri V, Restelli A, Marras E, Perletti G. A severely symptomatic case of anaerobic chronic bacterial prostatitis successfully resolved with moxifloxacin therapy. Anaerobe 2010; 16: 206-9.

8 Kermes K, Punab M, Lõivukene K, Mändar R. Anaerobic seminal fluid micro-flora in chronic prostatitis/chronic pelvic pain syndrome patients. Anaerobe 2003; 9: 11723.

9 Schaeffer AJ. Clinical practice. Chronic prostatitis and the chronic pelvic pain syndrome. N Eng/ J Med 2006; 355: 1690-8. 
10 Naber K, the European Lomefloxacin Prostatitis Study Group. Lomefloxacin versus ciprofloxacin in the treatment of chronic bacterial prostatitis. Int J Antimicrob Agents 2002; 20: 18-27.

11 Naber KG, Sorgel F. Antibiotic therapy-rationale and evidence for optimal drug concentrations in prostatic and seminal fluid and in pro-static tissue. Andrologia 2003; 35: 331-5.

12 Marcusson LL, Olofsson SK, Lindgren PK, Cars O, Hughes D. Mutant prevention concentrations of ciprofloxacin for urinary tract infection isolates of Escherichia coli. J Antimicrob Chemother 2005; 55: 938-43.

13 Mazzoli S. Biofilms in chronic bacterial prostatitis ( $\mathrm{NIH}-\mathrm{II})$ and in prostatic calcifications. FEMS Immunol Med Microbiol 2010; 59: 337-44.

14 Kanamaru S, Kurazono H, Terai A, Monden K, Kumon H et al. Increased biofilm formation in Escherichia coli isolated from acute prostatitis. Int J Antimicrob Agents 2006; 28 (Suppl 1): S21-5.

15 Soto SM, Smithson A, Martinez JA, Horcajada JP, Mensa J et al. Biofilm formation in uropathogenic Escherichia coli strains: relationship with prostatitis, urovirulence factors and antimicrobial resistance. J Urol 2007; 177: 365-8.

16 Perletti G, Wagenlehner FM, Naber KG, Magri V. Enhanced distribution of fourthgeneration fluoroquinolones in prostatic tissue. Int J Antimicrob Agents 2009; 33: 206-10.

17 Wagenlehner FM, Kees F, Weidner W, Wagenlehner C, Naber KG. Concentrations of moxifloxacin in plasma and urine, and penetration into prostatic fluid and ejaculate, following single oral administration of $400 \mathrm{mg}$ to healthy volunteers. Int J Antimicrob Agents 2008; 31: 21-6.

18 Magri V, Trinchieri A, Pozzi G, Restelli A, Garlaschi MC et al. Efficacy of repeated cycles of combination therapy for the eradication of infecting organisms in chronic bacterial prostatitis. Int J Antimicrob Agents 2007; 29: 549-56.

19 von Elm E, Altman DG, Egger M, Pocock SJ, Gotzsche PC et al. The Strengthening the Reporting of Observational Studies in Epidemiology (STROBE) statement: guidelines for reporting observational studies. Lancet 2007; 370: 1453-7.

20 http://www.uroweb.org/guidelines/

21 Nickel JC. Recommendations for the evaluation of patients with prostatitis. World J Urol 2003; 21: 75-81.

22 Stamey TA. Prostatitis. J R Soc Med 1981; 74: 22-40.

23 Magri V, Wagenlehner FM, Montanari E, Marras E, Orlandi V et al. Semen analysis in chronic bacterial prostatitis: diagnostic and therapeutic implications. Asian J Andro 2009; 11: 461-77.

24 Department of Reproductive Health and Research, World Health Organization. WHO Laboratory Manual for the Examination and Processing of Human Semen. 5th ed. Geneva: WHO Press; 2010.

$25 \mathrm{Kim}$ FY, Goldstein M. Antibacterial skin preparation decreases the incidence of falsepositive semen culture results. J Urol 1999; 161: 819-21.

26 Giubilei G, Mondaini N, Crisci A, Raugei A, Lombardi G et al. The Italian version of the National Institutes of Health Chronic Prostatitis Symptom Index. Eur Urol 2005; 47: 805-11.

27 Magri V, Trinchieri A, Montanari E, del Nero A, Mangiarotti B et al. Reduction of PSA values by combination pharmacological therapy in patients with chronic prostatitis: implications for prostate cancer detection. Arch Ital Urol Androl 2007; 79: 84-92.

28 Skerk V, Schoenwald S, Krhen I, Banaszak A, Begovac J et al. Comparative analysis of azithromycin and ciprofloxacin in the treatment of chronic prostatitis caused by Chlamydia trachomatis. Int J Antimicrob Agents 2003; 21: 457-62.

29 Skerk V, Krhen I, Lisić M, Begovac J, Cajic V et al. Azithromycin: 4.5- or 6.0-gram dose in the treatment of patients with chronic prostatitis caused by Chlamydia trachomatis - a randomized study. J Chemother 2004; 16: 408-10.

30 Wagenlehner FM, Naber KG. Current challenges in the treatment of complicated urinary tract infections and prostatitis. Clin Microbiol Infect 2006; 12 (Suppl 3): 67-80.

31 Morgia G, Mucciardi G, Galì A, Madonia M, Marchese F et al. Treatment of chronic prostatitis/chronic pelvic pain syndrome category IIIA with Serenoa repens plus selenium and lycopene (Profluss $®$ ) versus $S$. repens alone: an Italian randomized multicenter-controlled study. Urol Int 2010; 84: 400-6.

32 Rosen RC, Riley A, Wagner G, Osterloh IH, Kirkpatrick J et al. The International Index of Erectile Function (IIEF): a multidimensional scale for assessment of erectile dysfunction. Urology 1997; 49: 822-30.

33 Hatzimouratidis K, Amar E, Eardley I, Giuliano F, Hatzichristou D et al. Guidelines on male sexual dysfunction: erectile dysfunction and premature ejaculation. Eur Urol 2010; 57: 804-14.
34 Cliff N. Answering ordinal questions with ordinal data using ordinal statistics. Multivariate Behav Res 1996; 31: 331-50.

35 Feng D, Cliff N. Monte Carlo evaluation of ordinal $d$ with improved confidence interval. J Mod App/ Stat Methods 2004; 3: 322-32.

36 Cliff N. Ordinal Methods for Behavior Data Analysis. Hillsdale, , NJ: Lawrence Erlbaum; 1996. p208.

37 http://www.deakin.edu.au/ rodneyc/

38 http://www.r-project.org/

39 Bundrick W, Heron SP, Ray P, Schiff WM, Tennenberg AM et al. Levofloxacin versus ciprofloxacin in the treatment of chronic bacterial prostatitis: a randomized doubleblind multicenter study. Urology 2003; 62: 537-41.

40 Propert KJ, Litwin MS, Wang Y, Alexander RB, Calhoun E et al. Responsiveness of the National Institutes of Health Chronic Prostatitis Symptom Index (NIH-CPSI). Qual Life Res 2006; 15: 299-305.

41 Schaeffer AJ, Knauss JS, Landis JR, Propert KJ, Alexander RB et al. Leukocyte and bacterial counts do not correlate with severity of symptoms in men with chronic prostatitis: the National Institutes of Health Chronic Prostatitis Cohort Study. J Urol 2002; 168: 1048-53.

42 Wagenlehner FM, Naber KG, Bschleipfer T, Brahler E, Weidner W. Prostatitis and male pelvic pain syndrome: diagnosis and treatment. Dtsch Arztebl Int 2009; 106: 17583

43 Skerk V. Azithromycin in the treatment of chronic bacterial prostatitis. 20th European Congress of Clinical Microbiology and Infectious Diseases. Vienna, Austria, April 10 13, 2010. Clin Microbiol Infect 2010; 16 (Suppl 2): S42.

44 Nickel JC, Patel M, Cameron M. Chronic prostatitis/chronic pelvic pain syndrome: finding a way forward in the United Kingdom: report from the first United Kingdom Symposium on Chronic Prostatitis. Rev Urol 2008; 10: 160-3.

45 Foulds G, Madsen P, Cox C, Shepard R, Johnson R. Concentration of azithromycin in human prostatic tissue. Eur J Clin Microbiol Infect Dis 1991; 10: 868-71.

46 Schultz MJ. Macrolide activities beyond their antimicrobial effects: macrolides in diffuse panbronchiolitis and cystic fibrosis. J Antimicrob Chemother2004: 54:21-8.

47 Giamarellos-Bourboulis EJ. Macrolides beyond the conventional antimicrobsials: class of potent immunomodulators. Int J Antimicrob Agents 2008; 31: 12-20.

48 Amsden GW. Anti-inflammatory effects of macrolides - an underappreciated benefit in the treatment of community-acquired respiratory tract infections and chronic inflammatory pulmonary conditions? J Antimicrob Chemother 2005; 55: 10-21.

49 Parnham MJ. Immunomodulatory effects of antimicrobials in the therapy of respiratory tract infections. Curr Opin Infect Dis 2005; 18: 125-31.

50 Lee SW, Liong ML, Yuen KH, Leong WS, Cheah PY et al. Adverse impact of sexual dysfunction in chronic prostatitis/chronic pelvic pain syndrome. Urology 2008; 71 79-84.

51 Magri V, Montanari E, Marras E, Chiaffarino, Perletti G et al. Chronic prostatitis and erectile dysfunction: results from a cross-sectional study. Arch Ital Urol Androl 2008; 80: 172-5.

52 Mehik A, Hellstrom P, Sarpola A, Lukkarinen O, Jarvelin MR. Fears, sexua disturbances and personality features in men with prostatitis: a population-based cross-sectional study in Finland. BJU Int 2001; 88: 35-8.

53 Trinchieri A, Magri V, Cariani L, Bonamore R, Restelli A et al. Prevalence of sexual dysfunction in men with chronic prostatitis/chronic pelvic pain syndrome. Arch Ital Urol Androl 2007; 79: 67-70

54 Liang CZ, Zhang XJ, Hao ZY, Shi HQ, Wang KX. Prevalence of sexual dysfunction in Chinese men with chronic prostatitis. BJU Int 2004; 93: 568-570.

55 Sadeghi-Nejad H. Seftel A. Sexual dysfunction and prostatitis. Curr Urol Rep 2006; 7: 479-84.

56 Muller A, Mulhall JP. Sexual dysfunction in the patient with prostatitis. Curr Urol Rep 2006; 7: 307-12.

57 Smith KB, Pukall CF, Tripp DA, Nickel JC. Sexual and relationship functioning in men with chronic prostatitis/chronic pelvic pain syndrome and their partners. Arch Sex Behav 2007; 36: 301-11.

58 Geppetti P, Nassini R, Materazzi S, Benemei S. The concept of neurogenic inflammation. BJU Int 2008; 101 (Suppl 3): 2-6.

59 Magri V, Trinchieri A, Perletti G, Marras E. Activity of Serenoa repens, lycopene and selenium on prostatic disease: evidences and hypotheses. Arch Ital Urol Androl 2008, 80: 65-78.

60 El-Nashaar A, Shamloul R. Antibiotic treatment can delay ejaculation in patients with premature ejaculation and chronic bacterial prostatitis. J Sex Med 2007; 4: 491-6. 